Saudi Journal of Medical and Pharmaceutical Sciences

Abbreviated Key Title: Saudi J Med Pharm Sci

ISSN 2413-4929 (Print) | ISSN 2413-4910 (Online)

Scholars Middle East Publishers, Dubai, United Arab Emirates Journal homepage: https://saudijournals.com

\title{
Biomineralization from Nature to Applications
}

Vinay Kumar Srivastava ${ }^{1 *}$

${ }^{1}$ Associate Professor, Department of Chemistry D.S. College, Aligarh U.P. 202001, India

DOI: $10.36348 /$ sjmps.2022.v08i01.001 $\quad$ | Received: 26.11 .2021 | Accepted: 30.12 .2021 | Published: 07.01 .2022

*Corresponding author: Vinay Kumar Srivastava

Associate Professor, Department of Chemistry D.S. College, Aligarh U.P. 202001, India

\section{Abstract}

Biomineralization is the process by which living forms influence the precipitation of mineral materials. It provides organisms with skeletons and shells while they are alive and when they die they are deposited as sediment in environment from river, plants to the deep ocean floor. Biomineralization process is controlled by various factors like temperature, Organic matrix, additives, $\mathrm{pH}$ etc. Variety of applications of Biomineralization based technology in the construction has been reported. The Biomineralization is a multidisciplinary research area which briefly documents the future directions of the technology toward commercial scale applications.

Keywords: Calcium Carbonate, Mineralization, Factors, Applications.

Copyright ( 12022 The Author(s): This is an open-access article distributed under the terms of the Creative Commons Attribution 4.0 International License (CC BY-NC 4.0) which permits unrestricted use, distribution, and reproduction in any medium for non-commercial use provided the original author and source are credited.

\section{INTRODUCTION}

Biomineralization $[1,2]$ is the process by which living organisms manufactures precipitation of minerals for different functional purposes such as mechanical stiffening of tissue magnetite or gravitational sensing and element stroage. It is multidisciplinary field that draws on researchers from biology, chemistry, geology, nano-materials science and beyond. Teeth [3] which we use for breaking up food, bones which are essential for mechanical support, the shell (e.g. snail, mussels, oysters etc) protect the animal from predators when it is alive. The bones and the teeth of humans are by far the most intensively investigated mineralized tissues because of their considerable medical importance.

These materials have optical, mechanical and magnetic properties which are exploited by the organism for different purposes.

Researchers around the globe are now focusing on harnessing the technical applications of Biomineralization in various fields. In nature we are surrounded by biominerals in the form of beautiful corals, ant hills, caves, shells of mollusks rocks etc. as indicated in Fig.1. Many, living organisms ranging from bacteria to plants to animals can control the formation of minerals both within and around their cells. On the other hand one can define that Biomineralization is mineralization that happens in biological environments in which an organic matrix or soluble biomolecules along with biological environments in which an organic matrix or soluble biomolecules along with biological induced local environment, facilitate the crystallization of minerals and control their morphologies and location of nucleation. Examples include Iron and gold deposits in bacteria and other unicellular organisms, silicates in algae and diatoms, carbonates invertebrates and calcium, phosphates and carbonates in vertebrates. These minerals often form structural features such as sea shells and the bone in mammals and birds.

The formation of inorganic material with complex form is a wide spread biological phenomenon (biomineralization) that occurs in almost all groups of organisms from prokaryotes (e.g. magnetite nanocrystals in certain bacteria) to humans (bone and teeth).

\section{CLASSIFICATION OF BIOMINERALIZATION}

Biomineralization play an important role in the field of chemistry and it can be classify into three categories:

2.1 Crystallographic characterization, composition and biological chemistry of materials.

2.2 Testing hypotheses for the coordination between the organic matrix and the crystals and the role of biomacromolecules in controlling nucleation and crystals growth. 
Vinay Kumar Srivastava., Saudi J Med Pharm Sci, Jan, 2022; 8(1): 1-5

2.3 To develop biologically based new synthetic methods which are required for controlling morphology of crystals polymorph and material properties leading to new class of inorganic and organic composites. Organisms can impact mineral formation at different steps.

(a) Organism can modify actively or passively solution chemistry in their vicinity by changing $\mathrm{pH}$ or the activity of any chemical species.

(b) Organism can effect mineral growth i.e. it can inhibit crystal growth along certain directions by production of poisoning molecules forming minerals with specific shapes.

(c) Organisms can impact nucleation i.e. formation of very small and unstable mineral seeds.

It is therefore by definition Biomineralization a highly multidisciplinary field that spans both the inorganic and the organic world.

\section{TYPES OF BIOMINERALIZATION PROCESS}

3.1 Biologically Induced Mineralization (BIM): This type of Biomineralization results from the indirect modification of the chemistry of the environment by biological activity [4]. There is no control over size, morphology, structure and organization. Several types of microbial metabolisms can for example modify solution chemistry and induce carbonatation i.e. Precipitation of carbonate minerals including photosynthesis, sulfate reduction, urea degradation, ammonification or denitrification.

Nos of microbes involves in biologically induced mineralization process some of microbes are mycorrhiza, Lichen cynobacteria like Synechococcus SPP bacteria like Thilobacillus Ferroxidans, Sulfur reducing bacteria, Leptospirillum SPP.

Archea like Sulfolobus SPP, Acidimicrobium Ferroxidians SPP, acidianus SPP, Sulfurococcus yellowstonesis etc.

\section{Examples of Minerals by BIM}

(1) $\mathrm{CaCO}_{3}$ Precipitation in types of green algae

$\mathrm{Ca}^{++}+2 \mathrm{HCO}^{-} \square \mathrm{CaCO}_{3}+\mathrm{CO}_{2}+\mathrm{H}_{2} \mathrm{O}$.

(2) Metabolic removal of $\mathrm{CO}_{2}$ during photosynthesis

(3) $\mathrm{OH}$ fluxes are involved with precipitation of oxides, carbonates and phosphates.

(4) Some bacteria are able to accumulate and passivate toxic metal ions such as

$\mathrm{UO}^{2+}, \mathrm{Pb}^{2+}, \mathrm{Cd}^{2+}$, etc

(5) Biologically induced biomineralization could have an important role in clean-up of polluted water and soils.

\subsection{Biologically Controlled Mineralization (BCM):}

It is highly regulated process that has evolved to produce minerals with specific structures and functions. These biominerals are identified by their species - specific crystallochemical properties like uniform particle size, well defined structure and composition, complex morphologies, controlled aggregation and texture higher order assembly into hierarchical structure.

It produces minerals such as bones, shells and teeth that have specific biological functions and structures. Many microbes involves in BCM process some of microbes are magneto tactic bacteria diatoms, Emiliania huxleyi etc. Examples of minerals by BCM Magnetite: Magnetite formation done by magnetotatic bacteria which is microaerophilic, possess bidirectiona motility and contain membrane bounded a no. of intracellular linear arranged magnetosomes that contain magnetic crystals.

$$
\mathrm{Fe}^{2+}+2 \mathrm{OH}^{-}+2 \mathrm{Fe}(\mathrm{OH})_{3} \square \mathrm{Fe}_{3} \mathrm{O}_{4}+4 \mathrm{H}_{2} \mathrm{O}
$$

3.3 Biologically Influenced Bio mineralization (BIB): It is defined as passive mineralization of organic matter, whose properties influence crystal morphology and composition polysaccharides and protein have been shown to impact biomineralization in many cases (e.g. Obst etal 2009). It takes place when chemical conditions surrounding the site of mineral formation are influenced by abiotic processes (e.g. evaporation or degassing) However, the organic matrix (secreted by microorganisms) is responsible for crystal morphology and composition. Examples include micro to nanometer scale crystal of various morphologies. The term organomineralization is sometimes used encompassing biologically influenced and biologically induced biomineralization $[5,6]$.

\section{FACTORS AFFECTING BIOMINERALIZATION}

The formation of biominerals is often the result of the synergistic action of various factors such as temperature, $\mathrm{pH}$, Organic matrix and additives. As shown in Fig. No.-1 various factors which control the biomineralization are discussed as follows:

4.1 Effect of temperature and $\mathbf{p H}$ value: The solubility of salt in water depends upon temperature. As well as the solubility increases the temperature of salt will increase but it is opposite to the salt of calcium carbonate where the solubility is inversely proportional to temperature. As a result more calcium carbonate will deposit when the temperature increases. $\mathrm{pH}$ also plays an important role in the solubility in case of carbonate reducing $\mathrm{pH}$ value will increase the solubility of carbonate. 
Various crystal morphologies of calcium carbonate particles are controlled by temperature and $\mathrm{pH}$ values. The precipitation structure in Uranium VI $\left(\mathrm{UO}_{2}{ }^{2+}\right)$ Bio mineralization by Saccharomyces cerevisiae is controlled by $\mathrm{pH}$ factor. Passive precipitation or passive carbonatogenesis operated by producing carbonate and bicarbonate ions and inducing various chemical modifications in the medium e.g. an increase in $\mathrm{pH}$ value lead to the precipitation of calcium carbonate. Furthermore it is proved that factors temperature and $\mathrm{pH}$ produced a combined effect greater than the sum of their separate effect on biomineralization.

4.2 Organic matrix (OM): Biominerals synthesis of organic matrix involved in biomineralization processes. Organic matix [7] macromolecules such as proteins and polysaccharides play an important role in the process of biologically controlled Calcification. The organic matrix regulates different facets of crystal deposition such as the initiation of mineralization assembly in crystalline structures and inhibition thus the skeletal OM plays a key role in the whole biomineralization process. Protein is largely used in the formation of inorganic materials in the process of biomineralization which control the nucleation, growth, crystalline form, and trend of inorganic crystals. This whole process called molecular recognition.

4.3 Additives: Additives include soluble matrices extracted from shells and pearls, amino acids, magnesium ions and collagen among others. Amorphous calcium found in biomineralization both as transient precursor and a stable phase polyacrylic acid (PAA), hydroxypropyl methylcellulose (HPMC) were employed as additives controlling crystallization is important in many areas of science and technology. To obtain crystals with the desired structure and properties foreign substrates or additive are often introduced. Insoluble and soluble organic additives provide a heterogeneous nucleation and regulate crystal growth by their absorption. Soluble organic substances distribution and incorporation level in the calcium carbonate crystals can alter the growth kinetics and morphology of calcium carbonate, Amino acids, Peptides, copolymers, proteins etc. also contributed to shaping crystals when additive interaction takes place.

\section{APPLICATIONS}

Bio mineralization has great significance in scientific and commercial applications [8-10]. The application mainly includes drug and cell therapy engineering, cancer, tumor target engineering, Bone tissue enzyme engineering, 3D Printing Engineering, Environmental mechanical, Electrical, Microbial Engineering, Evolutionary biology and Geology. Bacterially induced carbonate biominerals is becoming increasingly now a days from removal of heavy metal and radionucleotides, removal of calcium from waste water and biodegradation of pollutants, atmospheric $\mathrm{CO}_{2}$ sequestration, remediation of building materials, modifying the properties of soil and filter in rubber and plastics to fluorescent markers in stationary ink, bacterial carbonates are serving many fields as shown in Fig.-2. In recent years molecular dynamics and other computational techniques have been applied to modeling crystal nucleation and growth. Harding et al.

[11] explained how these computational techniques are applied to range of biological and synthetic systems to provide insight into the role of the organic-inorganic interface in controlling crystallization. Weissbuch and Leiserowitz [12] explained the formation of hemozoin crystals by the parasite that causes malaria. Molecular recognition and Crystal design play an important role in developing novel treatments for malaria by inhibiting the growth of hemozoin crystals and thus poisoning the parasites.

\section{CONCLUSION AND PERSPECTIVES}

The process of biomineralization is relevant to the earth, environmental and life sciences on practically all length scales. The focus of biomineralization studies became a frontier area of research in the field of chemistry which is interacted between biological processes and organic chemistry. Biomineralization not only offers as excellent support to develop different types of nanomaterials to protect drugs cells, viruses from the physiological clearance during their transportation to target tumor but also increase the thermal cancer magnetic and optical properties of the nanomaterials for better real time imaging diagnosis and treatment of diseases. As a modification strategy biomineralization connects as well as blurs the boundary between inorganic and organic matters. Biomineralization is therefore an important interdisciplinary research area further development is expected in both fundamental and applied research. 

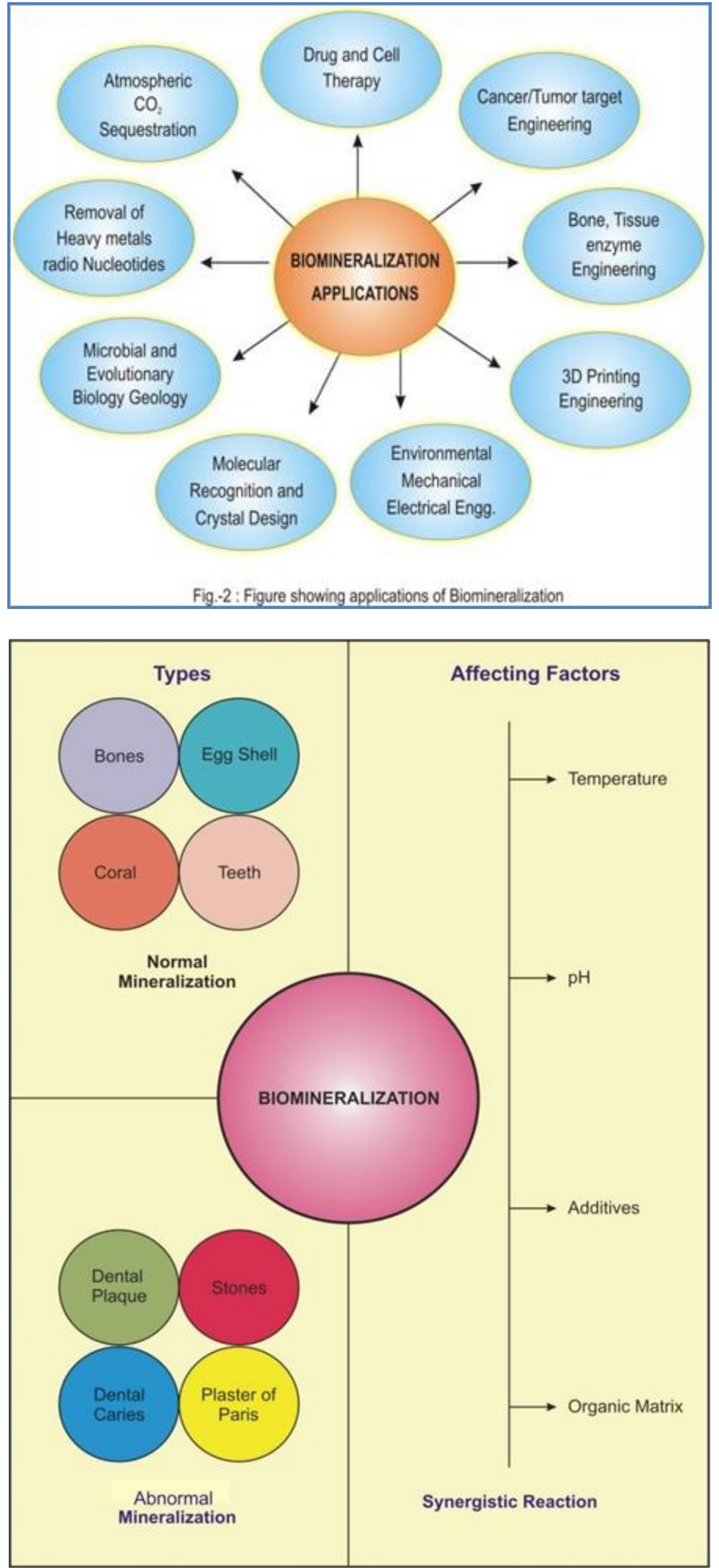

Fig. 1 : Schematics of types and affecting factors of Biomineralization Forming Process

\section{SUMMARY}

Bio mineralization is the process by which living forms influence the precipitation of mineral materials. It provides organisms with skeletons and shells while they are alive and when they die they are deposited as sediment in environment from river, plants to the deep ocean floor. Biomineralization process is controlled by various factors like Temperature, $\mathrm{pH}$ 
organic matrix, additives etc. Variety of applications of Biomineralization based technology in the construction has been reported.

The Biomineralization is a multidisciplinary research area which briefly documents the future directions of the technology toward commercial scale applications.

\section{REFERENCES}

1. Mann, S. (2001). Biomineralization: principles and concepts in bioinorganic materials chemistry (Vol. 5). Oxford University Press on Demand.

2. Lowenstam, H. A. (1981). Minerals formed by organisms. Science, 211(4487), 1126-1131.

3. Lowernstam, H.A., Weiner, S. (1989). On Bio mineralization, New York, NY: Oxford University Press.

4. Dupraz, C., Reid, R.P., Braissant, O., Decho, A.W., Norman, S.R., Visscher, P.T. (2009). Earth Sci Rev, 96, 141-162

5. Zhang, S., Jiang, Z., Qian, W., Shi, J., Wang, X., Tang, L., \& Liu, H. (2017). Preparation of Ultrathin, Robust Nanohybrid Capsules through a "Beyond Biomineralization" Method. ACS applied materials \& interfaces, 9(14), 12841-12850.

6. Yan, Y., Shi, X. R., Miao, M., He, T., Dong, Z. H., Zhan, K., \& Xia, B. Y. (2018). Bio-inspired design of hierarchical FeP nanostructure arrays for the hydrogen evolution reaction.

Nano Research, 11(7), 3537-3547.

7. Weiner, S., \& Hood, L. (1975). Soluble protein of the organic matrix of mollusk shells: a potential template for shell formation. Science, 190(4218), 987-989.

8. Holtus, T., Helmbrecht, L., Hendrikse, H. C., Baglai, I., Meuret, S., Adhyaksa, G. W., \& Noorduin, W. L. (2018). Shape-preserving transformation of carbonate minerals into lead halide perovskite semiconductors based on ion exchange/insertion reactions.
Nature chemistry, 10(7), 740-745.

9. Bauerlein, E. (2007). Handbook of Biomineralization. Weinheim: Wiley VCH

10. Lu, B. Q., Willhammar, T., Sun, B. B., Hedin, N., Gale, J. D., \& Gebauer, D. (2020). Introducing the crystalline phase of dicalcium phosphate monohydrate. Nature communications, 11(1), 1-8.

11. Beniash, E., Metzler, R. A., Lam, R. S., \& Gilbert, P. U. P. A. (2009). Transient amorphous calcium phosphate in forming enamel. Journal of structural biology, 166(2), 133-143.

12. Brown, W. E., \& Chow, L. C. (1976). Chemical properties of bone mineral. Annual Review of Materials Science, 6(1), 213-236.

13. Addadi, L., \& Weiner, S. (2014). Biomineralization: mineral formation by organisms. Physica Scripta, 89(9), 098003.

14. Weiner, S., \& Addadi, L. (2011). Crystallization pathways in biomineralization. Annual review of materials research, 41, 21-40.

15. Estroff, L.A. (2008). Introduction Bio mineralization Chem. Rev, 108; 4329-4331

16. Walsh, P., Fee, K., Clarke, S. (2018). Blue prints for the next Generation of Bio inspired And Biomimetic mineralized composites for Bone regeneration Mar. Drugs, 16, doi: 10.3390/md16080288.

17. Boskey, A.L. (1998). Bio mineralization conflicts, challenges and opportunities. Journal of Cellular Biochemistry Supplement, 30-31; 83-91

18. Porter, S.M. (2007). Sea water chemistry and early carbonate bio mineralization. Science, 316(5829); 1302

19. Harding, J., Freeman, C., Quigley, D., Rodger, P. (2012). Nucleation and growth of Biomaterials, 295-312.

20. Weissbuch, I., Leiserowitz, L. (2008). Interplay between malaria, crystalline Hemozoin formation and antimalarial drug action and design. Chem. Reviews, 108, 4899-914. 